\title{
E-exam Cheating Detection System
}

\author{
Razan Bawarith, Dr. Abdullah Basuhail, Dr. Anas Fattouh and Prof. Dr. Shehab Gamalel-Din \\ Computer Science \\ King AbdulAziz University \\ Jeddah, Saudi Arabia
}

\begin{abstract}
With the expansion of Internet and technology over the past decade, E-learning has grown exponentially day by day. Cheating in exams has been a widespread phenomenon all over the world regardless of the levels of development. Therefore, detection of traditional cheating methods may no longer be wholly successful to fully prevent cheating during examinations. Online examination is an integral and vital component of E-learning. Students' exams in E-learning are remotely submitted without any monitoring from physical proctors. As a result of being able to easily cheat during e-exams, E-learning universities depend on an examination process in which students take a face-to-face examination in a physical place allocated at the institution premises under supervised conditions, however this conflicts with the concept of distant Elearning environment. This paper will investigate the methods used by student for cheating detection in online exams, through continuous authentication and online proctors. In addition, we have implemented an E-exam management system, which is used to detect and prevent the cheating in online exams. The system used fingerprint reader authenticator and eye tribe tracker in exam session. We researched two parameters that can define the examinee status as cheating or non-cheating during exam. Through these two parameters: the total time on out screen and the number of times on out screen were computed.
\end{abstract}

Keywords-online exam; cheating; continuous authentication; online proctor; fingerprint; eye tracking

\section{INTRODUCTION}

In recent years, information and communication technologies (ICT) witnessed rapid developments and had direct impacts on human life, especially in the field of education. As a result, E-learning has become increasingly popular over the last few years and widely adopted by educational institutions. It enables to deliver information whenever students need at anytime and anywhere over the web. For this reason, it also called web-based learning or online learning. "Assessment for Learning is the process of seeking and interpreting evidence for use by learners and their teachers to decide where the learners are in their learning, where they need to go and how best to get there" [1]. Assessment is one of the main tasks of the education process. It takes an important weight during the development of any elearning course.

Exams are most widely used to assess student learning. However, exams can be classified into three types: traditional exams, online exams and distance exams (D-exams). Traditional exam defined as a set of questionnaires given in the class. They are created based on static questions per student. As a result, students must begin and end the exam within the same time limits. Online exams, sometimes referred to as eexamination, are Internet based questionnaire. They are created randomly from questions set per student with a preset time limits by which the exam is to be completed. Furthermore, students should attend to a classroom for performing an exam.

D-exams are a way of delivering questions to students who are not physically present in a traditional setting such as a classroom. They are created randomly from questions set per student with a preset time limit by which they should be answered. Furthermore, they save or reduce time required for paper checking, as well as, they save papers, and printing, thus saving environment. D-exam present a new challenges for teachers; notably, how to prevent students from cheating. As a result, e-learning institutions depend on an examination process in which students take a face-to-face examination in a physical place located at the institution premises and under supervised conditions to ensure the student identity. However, that conflicts with the concept of E-learning, which eliminates the temporal and spatial dimensions between the students and the learning process. Each student must be physically present in the classroom in order to take the exam.

This paper investigates all types of methods used for cheating in D-exam, and resolves this problem by either detection or prevention. Detecting and preventing cheating require a human intervention (i.e. the presence of a proctor). The proctor needs to physically authenticate students' IDs before starting the exam. However, this is not enough; we need continuous authentication all over the exam session. In addition, we need a continuous process of monitoring and controlling over all students during the exam period.

The rest of this paper organized as follows: Section II describes cheating, Section III depicts authentication, Section IV describes online proctor, Section V introduces the e-exam management system architecture, Section VI presents the eexam management system algorithm, Section VII presents the implementation of e-exam management system, Section VIII presents the experimental results, Section IX provides conclusions, and Section X provides future work.

\section{CHEATING}

Cheating on exams has been a widespread phenomenon in the world regardless of the levels of detection development. Many studies have been conducted over the past decade about cheating activities performed by students and the means by which university could attempt to combat this problem [2]. In the U.S., it was revealed that $80 \%$ of the higher achieving secondary school students admitted to cheat in during exams, $95 \%$ of secondary school students who admitted cheating said 
that they had not been caught, $51 \%$ of secondary school students did not believe cheating was wrong, $85 \%$ of college students said cheating was necessary to get ahead, $75 \%$ of college students admitted cheating in exams, and $90 \%$ of college students did not believe cheaters would be caught [3].

The most common reasons that motivate students to cheat include: pressure from parents to do well, fear of failure, unclear instructional objectives, desire for a better grade, everyone else is doing it, there is no punishment if being caught, there is little chance of being caught, and no time to study and easy access to online information [4].

Many students still use traditional cheating methods that are defined as each student can be cheating by own self or others. Cheating that appears in online exam is called online cheating. A student can be cheating via the Internet.

Table I illustrates the different types of cheating in traditional exams and in online exams. In addition, it presents some of the suggested solutions to prevent cheating. By proctor, we mean a person who monitors or invigilates exams.

TABLE. I. TYPE OF CHEATING

\begin{tabular}{|c|c|c|c|c|}
\hline \multirow[b]{2}{*}{ Type of cheating } & \multicolumn{2}{|c|}{ Traditional Cheating } & \multicolumn{2}{|c|}{ Online Cheating } \\
\hline & $\begin{array}{l}\text { Preventio } \\
n\end{array}$ & Detection & $\begin{array}{l}\text { Preventio } \\
n\end{array}$ & Detection \\
\hline $\begin{array}{l}\text { Using cheating } \\
\text { sheets: prewritten } \\
\text { cheat sheets, usually } \\
\text { in small font, hidden } \\
\text { in clothes or under } \\
\text { wrist watch [5] }\end{array}$ & & $\begin{array}{l}\text { Seek help } \\
\text { from } \\
\text { physical } \\
\text { proctors }\end{array}$ & & $\begin{array}{l}\text { Seek help } \\
\text { from } \\
\text { physical } \\
\text { proctors }\end{array}$ \\
\hline $\begin{array}{l}\text { Using cheating sheet } \\
\text { on the floor: } \\
\text { prewritten cheating } \\
\text { sheets hidden in } \\
\text { books or under } \\
\text { folders below the } \\
\text { desk [5] }\end{array}$ & $\begin{array}{l}\text { Make sure } \\
\text { that books } \\
\text { or notes } \\
\text { are stored } \\
\text { in } \\
\text { backpack, } \\
\text { not under } \\
\text { desk }\end{array}$ & $\begin{array}{l}\text { Seek help } \\
\text { from } \\
\text { physical } \\
\text { proctors }\end{array}$ & $\begin{array}{l}\text { Make sure } \\
\text { that books } \\
\text { or notes } \\
\text { are stored } \\
\text { in } \\
\text { backpack, } \\
\text { not under } \\
\text { desk } \\
\end{array}$ & $\begin{array}{l}\text { Seek help } \\
\text { from } \\
\text { physical } \\
\text { proctors }\end{array}$ \\
\hline $\begin{array}{l}\text { Using numeric } \\
\text { devices to } \\
\text { communicate a } \\
\text { question number or } \\
\text { correct answer by } \\
\text { text messaging via } \\
\text { cell phones [6] }\end{array}$ & $\begin{array}{l}\text { Don't } \\
\text { allow cell } \\
\text { phones or } \\
\text { use a } \\
\text { Microsoft } \\
\text { Dongle to } \\
\text { detect any } \\
\text { Devices } \\
\text { with } \\
\text { Bluetooth } \\
\text { technolog } \\
\text { y in the } \\
\text { "on" } \\
\text { Position }\end{array}$ & $\begin{array}{l}\text { Seek help } \\
\text { from } \\
\text { physical } \\
\text { proctors }\end{array}$ & $\begin{array}{l}\text { Don't } \\
\text { allow cell } \\
\text { phones or } \\
\text { use a } \\
\text { Microsoft } \\
\text { Dongle to } \\
\text { detect any } \\
\text { Devices } \\
\text { with } \\
\text { Bluetooth } \\
\text { technolog } \\
\text { y in the } \\
\text { "on" } \\
\text { Position }\end{array}$ & $\begin{array}{l}\text { Seek help } \\
\text { from } \\
\text { physical } \\
\text { proctors }\end{array}$ \\
\hline $\begin{array}{l}\text { Listening to the ipod } \\
\text { which has recording } \\
\text { abilities; It is } \\
\text { possible to hide } \\
\text { earphone wires } \\
\text { behind long hair [5] }\end{array}$ & $\begin{array}{l}\text { Don't } \\
\text { allow } \\
\text { examinees } \\
\text { to use } \\
\text { ipods }\end{array}$ & $\begin{array}{l}\text { Seek help } \\
\text { from } \\
\text { physical } \\
\text { proctors }\end{array}$ & $\begin{array}{l}\text { Don't } \\
\text { allow } \\
\text { examinees } \\
\text { to use } \\
\text { ipods }\end{array}$ & $\begin{array}{l}\text { Seek help } \\
\text { from } \\
\text { physical } \\
\text { proctors }\end{array}$ \\
\hline
\end{tabular}

D-exam is an efficacious manner to conduct an examination. Students can study from any convenient place. Moreover, there is no need for physical transfer. However, it faces the problem of cheating during examinations since there are no physical proctors invigilate and control the exam. This referred to as distance cheating. Distance cheating includes all previously mentioned kinds of cheating. In addition, there are other forms of cheating, such as: taking an examination for another student or having someone take an examination for one, using applications that help to solve the exam questions, copying test questions and sending them to an expert to send back the answers, and downloading resources from the Internet, for example, using an e-book .

\section{AUTHENTICATION}

Authentication is one of the methods that are designed to protect personal identity [7]; also, it attempts to verify that the users are those who claim to be. Unlike face-to-face examinations, D-exam have no proctors or invigilators. They are held at a different and an uncontrolled remote environments. As a result, authentication goals in D-exam are important to check the identity of online students since it plays a key role in security [8,9].

There are two kinds of authentication [7]: static authentication and continuous authentication. Static authentication refers to authentication that takes place at the beginning of accessing the examination, and will also be valid during the whole period until the user logs off from that examination. The continuous authentication refers to authentication that will be continued after the start of the examination, and will verify whether the current user is the same as the user who initiated the exam or not.

\section{A. Continuous Authentication Technique}

\section{1) Fingerprint}

Fingerprint authentication refers to the automated method of verifying a match between two human fingerprints. Fingerprint identification is one of the most wellknown and publicized biometrics, because of its uniqueness and consistency over time. No two people have exactly the same fingerprints. Even identical twins, with identical DNA, have different fingerprints. This uniqueness allows fingerprints to use in all sorts of ways, including background checks [10]. Fingerprint offers many advantages such as uniqueness, convenience, non-repudiation and non-transferable.

Fingerprint recognition operates in two distinct modules, as shown in Fig 1, [11]. First, the enrollment module: an application to be used by a user to capture multiple fingerprints for at least two fingers by a fingerprint reader. In addition, it checks image quality to ensure that a good quality scanned image is captured. In addition, it extracts the fingerprint minutiae and saves the entire fingerprint images and/or minutiae in a database. The verification module: an application that verifies users. It can capture a fingerprint from a fingerprint reader. In addition, it extracts the fingerprint minutiae. In addition, it compares fingerprint with stored fingerprints to identify a user from a list or verify a specific user. 


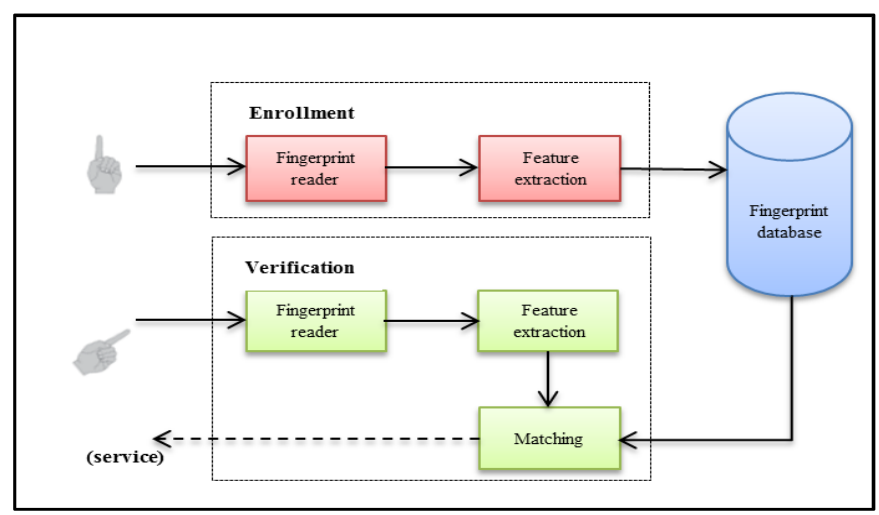

Fig. 1. Fingerprint Recognition

\section{2) Eye Tracking}

Eye tracking is a technology that calculates the eye gaze point of a user as he or she looks around. The eye gaze coordinates are calculated with respect to a screen the person is looking at, and are represented by a pair of $(\mathrm{x}, \mathrm{y})$ coordinates given on the screen coordinate system [12].

Eye tracking can be used in a wide variety of applications, typically categorized as active or passive. Active applications involve device control, for example aiming in games, eye activated login or hands-free typing. Passive applications include performance analysis of design, layout and advertising. Other examples are vehicle safety, medical diagnostics and academic research [13].

\section{ONLINE PROCTOR}

Online proctor (e-proctor) is another technique, which is planned to be investigated for the objective of monitoring a student while he/she is taking a D-exam. The e-proctor role is to detect any cheating activities during a D-exam session.

E-Proctor is an integrated solution that brings academic integrity to distance learning exams. The e-proctor requires a fingerprint scanner to authenticate the identity of a student, and it requires an eye tracker that contains a camera to track the user's eyes movements, as shown in Fig 2. The camera tracks even the most minuscule of movements of the users' pupils, by taking the images and running them through computer-vision algorithms. The algorithms read, "On-screen gaze coordinates", and then, help the software to determine where on the screen the user is looking. E-proctor is connected to the student' computer, it locks the computer system to only the exam application while simultaneously prohibiting access to all other applications or pre-existing information which could be used for cheating during an exam.

The student must successfully pass through the ID authentication process that entails placing the finger on a scanner and will match the biometrics with the information gathered during the initial registration process. In addition, student needs a personal calibration process. Each person has different eye characteristics. The eye tracking needs to locate the gaze accurately. The calibration consists of a circular target that displayed at different locations of the screen on a blank background for around 2 seconds each. The user needs to look at the target as it is displayed on the screen. Once all the calibration targets displayed on the screen, the calibration process is completed.

Once the student identification authenticated and the calibration process completed successfully, E-proctor launches the exam application for the student while locking his computer until the exam completed. During the exam, eproctor will record changes in the eyes movement.

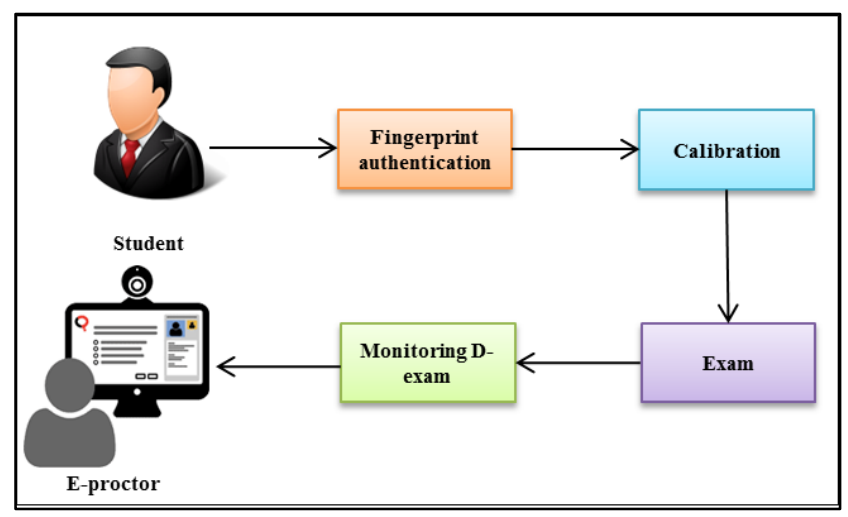

Fig. 2. Online Proctor

\section{E-EXAM ManAgEMENT System ARChitecture}

The work of e-exam management system can be divided into two phases as depicted in Fig 3. The first phase is before being permitted to perform the E-exam session, username/password and fingerprints must be used to authenticate the examinee. The second phase is during the exam session, it is required to continuously guarantee that the examinee is the one who is claiming to be. Eye tracking is utilized during the E-exam session.

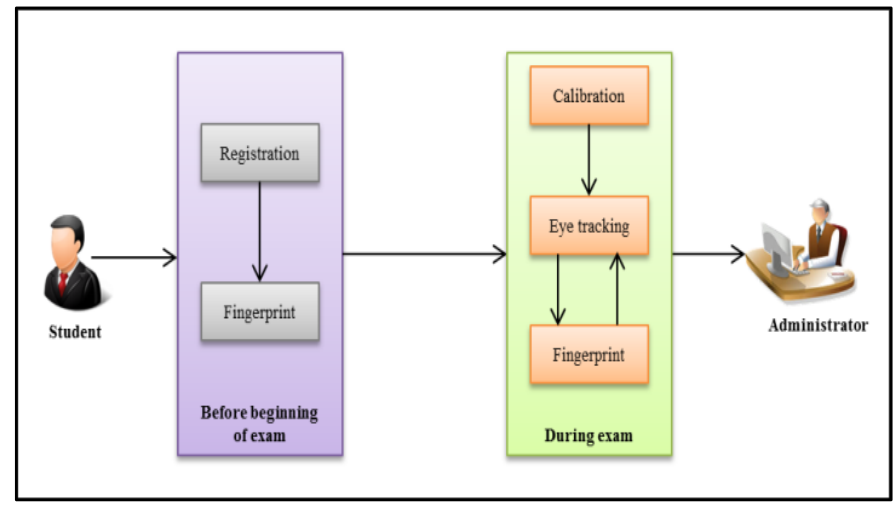

Fig. 3. The Architecture of E-Exam Management System

Before starting exam session, the system's user, i.e. examinee, first must create an account. The user will be required to provide his/her examinee user name and password. After registration, the examinee will be able to enroll the fingerprint into the system.

In the second phase, the examinee is continuously authenticated through an eye tracking to prevent any cheating situation. Eye tracking is the process of using sensors to locate features of the eyes and estimate to where the examinee is looking (point of gaze). The tracker must be placed below the 
screen and pointing at the examinee. The examinee needs to be located within the tracker's trackbox. A trackbox is a small graphical component that illustrates an examinee's position relative to the sensor. This is useful to see if examinee is within the range of the sensor and the tracking is fully functional. Afterwards, the examinee will now be ready to the calibration process. The calibration process requires of examinee to look at a series of calibration targets distributed evenly throughout the screen. Each target will appear one after the other and they are displayed for a predefined periods. The process usually takes about 20 seconds to complete. After successful completion of the calibration process, the examinee will be able to log into the E-exam. The examinee will be continuously authenticated through an eye tracker; eye trackers may be able to prevent any cheating status during E-exam.

To achieve the continuous authentication in E-Exam Management system via eye tracker, the system needs to distinguish between three scenarios as shown in Fig 4.

- Scenario 1: The examinee is in front of the screen and his frontal eyes view is available to the camera.

- Scenario 2: The examinee is sitting in front of the screen, but he is looking down.

- Scenario 3: The examinee has moved away from the screen.

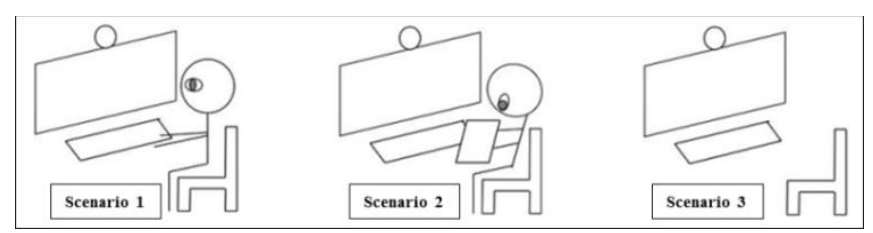

Fig. 4. Scenarios of Eye Tracking

In scenario 1 ; the system is unlooked the exam, because examinee is active and in front of the screen, also the system can be monitoring the examinee via eye tracker. In scenario 2 and scenario 3, the system locked the exam; because user is not active or moves away from the screen, furthermore the system must be re-authenticate examinee automatically.

\section{E- EXAM MANAGEMENT SYSTEM ALGORITHM}

E-exam management system that we suggested in this paper consisted of several modules that perform the functions of the system. Fig 5 demonstrates flowchart of the algorithm of the E-exam management system.

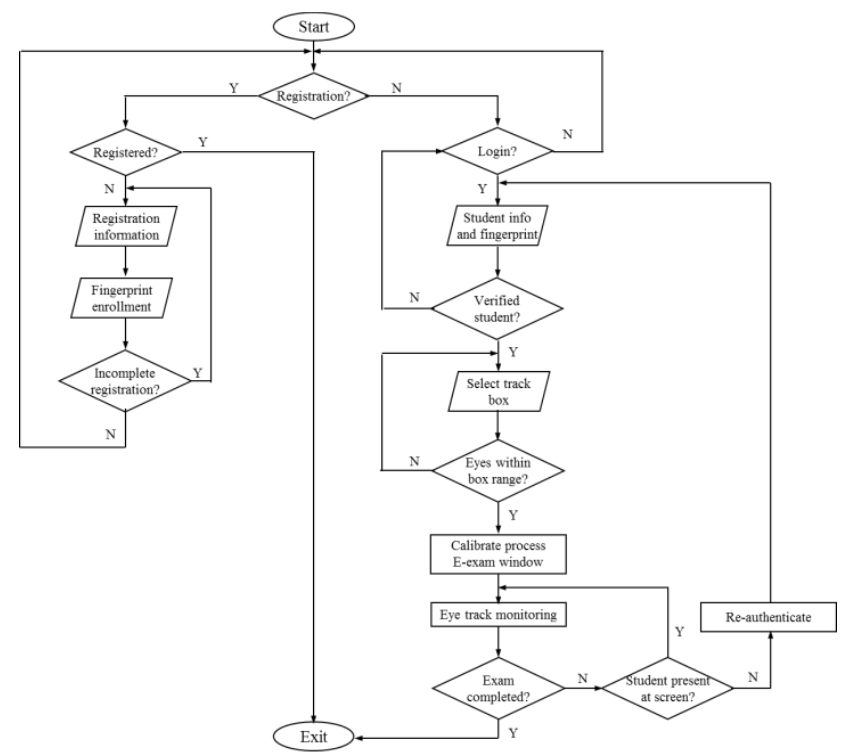

Fig. 5. Flowchart of E-Exam Management System

\section{IMPLEMENTATION OF E-EXAM MANAGEMENT SySTEM}

E-Exam Management system is implemented using visual C\# 2012 and SQL server 2008 database. In addition, we used some tools such as digital persona U.Are.U 4500 HD USB Fingerprint Reader, and Eye Tribe Tracker. The following is a snapshot of the E-exam window of the eye tracker monitoring. Any time the E-system recognizes that the examinee is no longer present in front of the screen; the system is locked and must re-authenticate the examinee automatically via fingerprint, as shown in Fig 6.

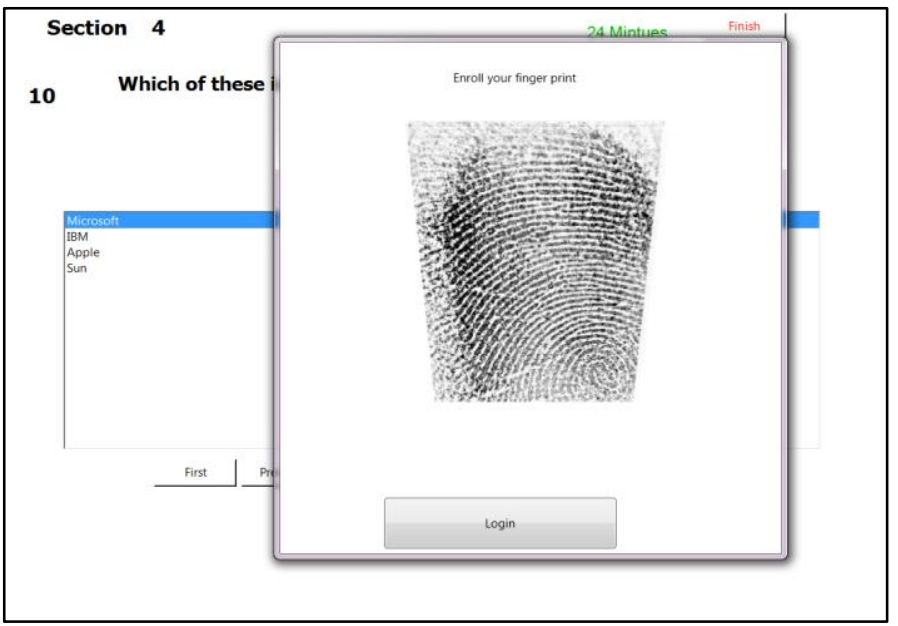

Fig. 6. E-Exam Windows 


\section{ANALYSIS AND EVALUATION}

The E-exam management system is utilized to detect any status of cheating in D-exam. We used the fingerprint reader for continuous examinee authentication and the eye tracker for the observation of the examinee through the D-exam session.

The experiments involved 30 participants with a diverse range of jobs, backgrounds and education levels. Participants were divided into two groups: the first group consisted of 15 participants who were in status of cheating during the D-exam, and the second group was 15 participants who were in status of non-cheating during the D-exam. In addition, each participant repeated the experiment three times. So the size of data equals 90 samples in this experiment.

We observed the participant in D-exam via the eye tracker. The tracker registers the movements of the participant's eyes in a database. The database contains the user ID of the examinee, the time when the examinee get out of the screen, the time when the examinee come back to the screen, and the cheating status. Tables II show samples of collected data.

TABLE. II. SAMPLES OF COLLECTED DATA

\begin{tabular}{|l|l|l|l|}
\hline ID & $\begin{array}{l}\text { Average time } \\
\text { out of the screen } \\
\text { (Second) }\end{array}$ & $\begin{array}{l}\text { Average } \\
\text { number of times } \\
\text { out of the screen }\end{array}$ & Status \\
\hline 1 & $0: 11: 57$ & 19 & non- cheating \\
\hline 2 & $0: 12: 52$ & 6 & non- cheating \\
\hline 3 & $0: 01: 38$ & 10 & non- cheating \\
\hline 4 & $0: 06: 28$ & 28 & non- cheating \\
\hline 5 & $0: 02: 29$ & 16 & non- cheating \\
\hline 6 & $0: 01: 31$ & 12 & non- cheating \\
\hline 7 & $0: 14: 23$ & 32 & cheating \\
\hline 8 & $0: 14: 50$ & 25 & cheating \\
\hline 9 & $0: 12: 07$ & 25 & cheating \\
\hline 10 & $0: 12: 18$ & 21 & cheating \\
\hline 11 & $0: 16: 55$ & 11 & cheating \\
\hline 12 & $0: 15: 06$ & 21 & cheating \\
\hline
\end{tabular}

A scatter plot of the data is shown in Fig 7.

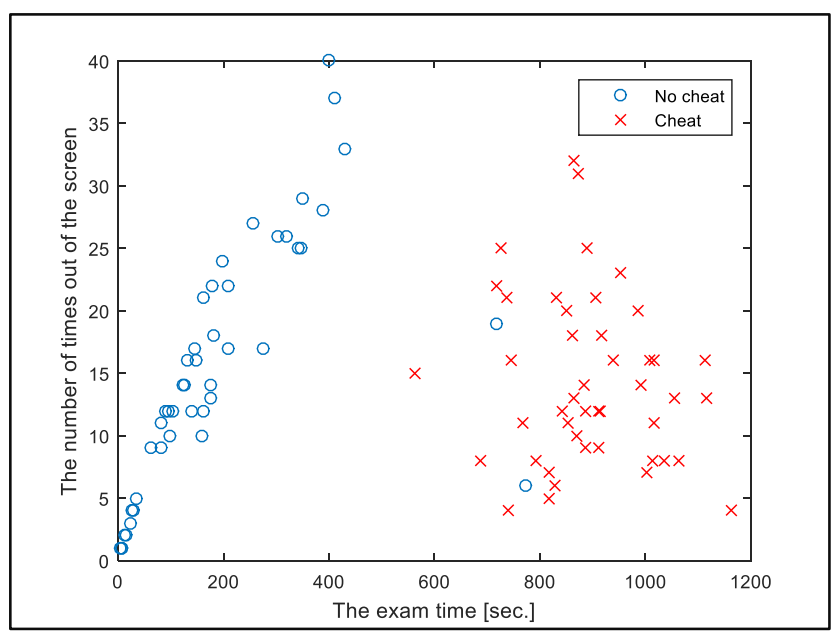

Fig. 7. Scatter Plot of 90 Samples

We can discriminate between "cheating" case and "no cheating" case by dividing the plane into two regions by a line defined by the two points $\mathrm{p}_{1}(300,0)$ and $\mathrm{p}_{2}(600,40)$ as shown in Fig 8 .

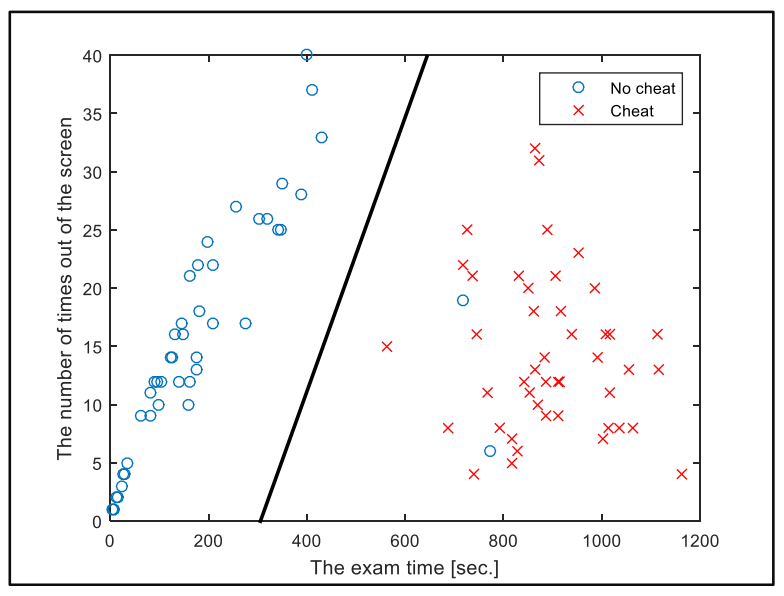

Fig. 8. Scatter Plot of 90 Samples with a Separation Line

Let $\mathrm{t}$ be the exam time and $\mathrm{n}$ be the number of times out of the screen, then the equation of the line is:

$$
\mathrm{n}=\mathrm{m} \mathrm{t}+\mathrm{b}
$$

Where $m$ is the slope of the line and $b$ is the intercept. They can calculate as follows.

$$
\begin{aligned}
\mathrm{m} & =\frac{\Delta \mathrm{n}}{\Delta \mathrm{t}}=\frac{40-0}{600-300}=0.1333 \\
b & =n-m t=0-0.1333 \times 300=-40
\end{aligned}
$$

Therefore, the equation of the line is:

$$
n=0.1333 t-40
$$

Any sample $s\left(t_{s}, n_{s}\right)$ can be classified using equation (4) as follows:

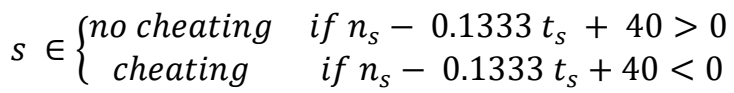

Using the classifier defined by the equation (5), the 90 samples can classified as shown in Fig 9.

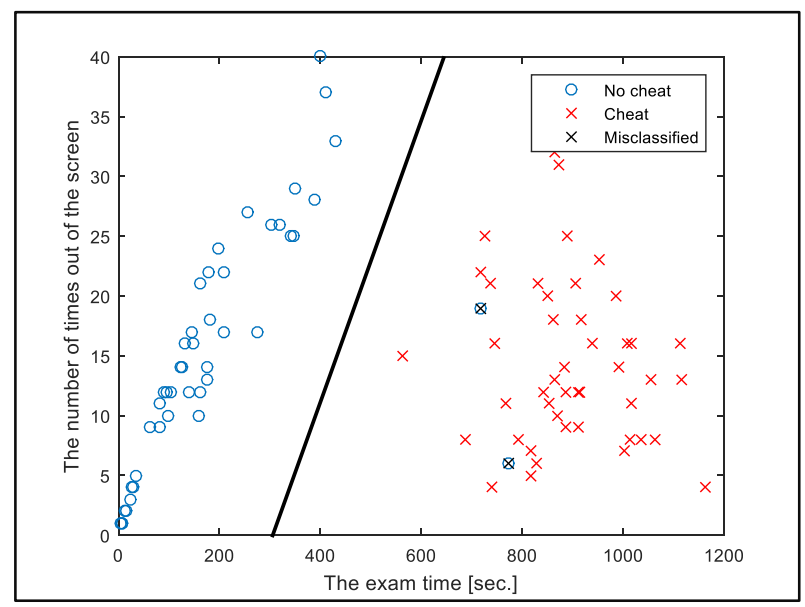

Fig. 9. Classifying the 90 Samples using Equation (5)

A confusion matrix, also known as a contingency table used to indicate the results of the recall, specificity, precision, and accuracy measures [14]. The confusion matrix contains four cells:

- TP: Number of true items on the classified positive samples. 
- FP: Number of false items on the classified positive samples.

- TN: Number of true items on the classified negative samples.

- FN: Number of false items on the classified negative samples.

The confusion matrix given by:

TABLE. III. CONFUSION MATRIX

\begin{tabular}{|l|l|l|}
\hline & Predicted No & Predicted Yes \\
\hline Actual No & 43 & 2 \\
\hline Actual Yes & 0 & 45 \\
\hline
\end{tabular}

Therefore, $\mathrm{TN}=43, \mathrm{FP}=2, \mathrm{FN}=0$, and $\mathrm{TP}=45$. In addition, the performance of the Table III is measured as follows:

- Sensitivity (Recall) which is measures the proportion of positives that correctly identified, also called the true positive rate.

Sensitivity $($ Recall $)=\mathrm{TP} /(\mathrm{TP}+\mathrm{FN})=100 \%$

- Specificity, which is, measures the proportion of negatives that correctly identified also called the true negative rate.

Specificity $=\mathrm{TN} /(\mathrm{FP}+\mathrm{TN})=95.56 \%$

- Precision is the fraction of retrieved instances that are relevant, also called positive predictive value.

Precision $=\mathrm{TP} /(\mathrm{TP}+\mathrm{FP})=95.74 \%$

- Accuracy is the proximity of measurement results to the true value.

Accuracy $=(\mathrm{TP}+\mathrm{TN}) /(\mathrm{TP}+\mathrm{TN}+\mathrm{FP}+\mathrm{FN})=97.78 \%$

- F-measure :A measure that merges both the precision and the recall, also called the harmonic mean.

F-measure $=2 * \mathrm{TP} /(2 * \mathrm{TP}+\mathrm{FN}+\mathrm{FP})=97.83 \%$

\section{CONCLUSION}

This paper addresses the cheating in online exam. Specifically, it introduced the concepts of cheating and how it can be controlled in online exam. It provides a technique for detecting and preventing student from cheating through continuous authentication and online proctor. E-exam management system is proposed to investigate cheating in Dexam using Fingerprint Reader to authenticate the examinee, and Eye Tribe Tracker to continuously guarantee that the examinee is the one who is claiming to be. This system was developed in visual C\# and SQL server database. As a result, the system classified the examinee status as cheating or noncheating based on two parameters: the total an examinee time on out screen and the number of times, the examinee is out of screen. To evaluate this proposed work, a series of experimental tests were conducted. The tests yielded the following results: sensitivity is $100 \%$, specificity is $95.56 \%$, precision is $95.74 \%$, accuracy is $97.78 \%$, and f-measure is $97.83 \%$.

There are some limitations for the system that we presented in this paper, such as the handling of the cases of students with special needs.

\section{FUTURE WORK}

There are several promising directions to extend the work presented in this research. The system can be implemented over the web. Another feature to improve continuous authentication such as voiceprint that is integrated and utilized during the D-exam session can be added to the system. Using face recognition as continuous authentication which can identify a specific individual in a digital image by analyzing and comparing patterns. Still one more enhancement can be made is that, after a student start an exam, the use of keystrokes as continuous authentication that will control whether the current user is the same as the user who initiated the static authentication or not.

[1] Assessment Reform Group, "Assessment for Learning: 10 Principles,"2002. [Online]. Available: https://assessmentreformgroup.files.wordpress.com/2012/01/10principle s_english.pdf\&gt [Accessed: 23- Mar- 2017].

[2] K. Curran, G. Middleton and C. Doherty, "Cheating in exams with technology," $2011 . \quad$ [Online].Available: https://pdfs.semanticscholar.org/1ba7/bc7b96f0bbc3ecbbcd958f9bd7558 52c1c02.pdf [Accessed: 23- Mar- 2017].

[3] J. Kerkvliet and C.L. Sigmund, "Can we control cheating in the classroom? ," The Journal of Economic Education, vol. 30(4), pp.331343, 1999.

[4] B. Keresztury and L. Cser, "New cheating methods in the electronic teaching era," Procedia-Social and Behavioral Sciences, vol .93, pp.1516-1520, 2013.

[5] K. Yee and P. MacKown ," Detecting and preventing cheating during exams," PEDAGOGY, NOT POLICING, p.141, 2009.

[6] D. Faucher and S. Caves, "Academic dishonesty: Innovative cheating techniques and the detection and prevention of them," Teaching and Learning in Nursing, vol .4(2), pp.37-41, 2009.

[7] P. Bours and H. Barghouthi, "Continuous authentication using biometric keystroke dynamics," Norwegian Information Security Conference (NISK), November 2009.

[8] Ullah, H. Xiao and M. Lilley, "Profile based student authentication in online examination," International Conference on Information Society (i-Society 2012), London, 2012, pp. 109-113.

[9] Ullah, H. Xiao and M. Lilley and T. Barker, "Using challenge questions for student authentication in online examination," International Journal for Infonomics (IJI), vol .5(3/4), pp.9, 2012.

[10] S.D. Patil and S.A. Patil, "Fingerprint recognition using minutia matching," World Journal of Science and Technology, vol .2(4), pp.178$181,2012$.

[11] M. Lourde and D. Khosla, "Fingerprint Identification in Biometric SecuritySystems," International Journal of Computer and Electrical Engineering, vol .2(5), p.852, 2010.

[12] B.S. Bagepally, "Gaze Pattern on Spontaneous Human Face Perception: An Eye Tracker Study," Journal of the Indian Academy of Applied Psychology, vol .41(3), p.127, 2015.

[13] "The eye tribe ," 2016. Available at: https://theeyetribe.com [Accessed: 23- Mar- 2017].

[14] [14] Y.S. Chang and H.T. Cheng, "A scientific data extraction architecture using classified metadata," The Journal of Supercomputing, vol.60(3), pp.338-359, 2012. 